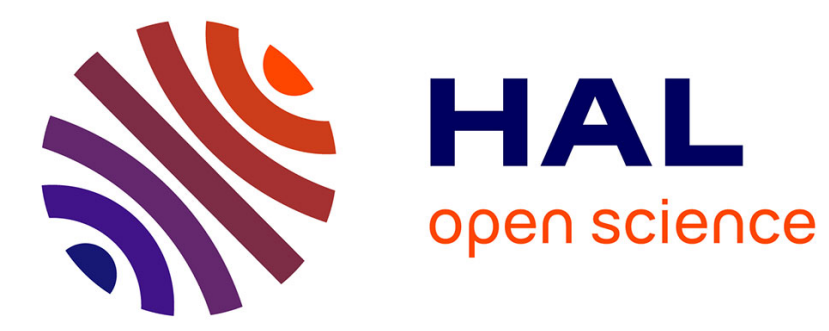

\title{
Hyperinsulinemia and insulin signalling in the pathogenesis and the clinical course of hepatocellular carcinoma
}

\author{
Hamza Chettouh, Marie Lequoy, Laetitia Fartoux, Corinne Vigouroux, \\ Christèle Desbois-Mouthon
}

\section{To cite this version:}

Hamza Chettouh, Marie Lequoy, Laetitia Fartoux, Corinne Vigouroux, Christèle Desbois-Mouthon. Hyperinsulinemia and insulin signalling in the pathogenesis and the clinical course of hepatocellular carcinoma. Liver International, 2015, 35 (10), pp.2203-2217. 10.1111/liv.12903 . hal-01196347

\section{HAL Id: hal-01196347 https://hal.sorbonne-universite.fr/hal-01196347}

Submitted on 9 Sep 2015

HAL is a multi-disciplinary open access archive for the deposit and dissemination of scientific research documents, whether they are published or not. The documents may come from teaching and research institutions in France or abroad, or from public or private research centers.
L'archive ouverte pluridisciplinaire HAL, est destinée au dépôt et à la diffusion de documents scientifiques de niveau recherche, publiés ou non, émanant des établissements d'enseignement et de recherche français ou étrangers, des laboratoires publics ou privés. 


\title{
Hyperinsulinemia and insulin signalling in the pathogenesis and the clinical course of hepatocellular carcinoma
}

\author{
Hamza Chettouh ${ }^{1,2}$, Marie Lequoy ${ }^{1,2,3}$, Laetitia Fartoux ${ }^{1,2,3}$, Corinne Vigouroux ${ }^{1,2,4,5}$, \\ Christèle Desbois-Mouthon $(\bowtie)^{1,2}$ \\ ${ }^{1}$ Sorbonne Universités, UPMC Univ Paris 06, UMR_S 938, Centre de Recherche Saint-Antoine, F- \\ 75012, Paris, France \\ ${ }^{2}$ INSERM, UMR_S 938, Centre de Recherche Saint-Antoine, F-75012, Paris, France \\ ${ }^{3}$ AP-HP, Hôpital Saint-Antoine, Service d'Hépatologie, F-75012, Paris, France \\ ${ }^{4}$ AP-HP, Hôpital Saint-Antoine, Laboratoire Commun de Biologie et Génétique Moléculaires, F-75012, \\ Paris, France \\ ${ }^{5}$ ICAN, Institute of Cardiometabolism and Nutrition, F-75013, Paris, France
}

Corresponding author: $\operatorname{Dr}$ Christèle Desbois-Mouthon, Saint-Antoine Research Centre, INSERM - UPMC UMRS_938, Team "Biology and Treatment of Hepatobiliary Tumours ", 184 rue du Faubourg Saint-Antoine, 75571 PARIS Cedex 12, Paris, France; phone: 331492846 98; e-mail: christele.desbois-mouthon@inserm.fr

Word count: 6,366; Figure number: 2

Abbreviations: $\mathrm{BMI}$, body mass index; $\mathrm{Cl}$, confidence interval; $\mathrm{CLD}$, chronic liver disease; EPIC, european prospective investigation into cancer and nutrition; FOXO1, Forkhead box 01; G6PC, glucose 6-phosphatase catalytic subunit ; HBV, hepatitis $B$ virus; $\mathrm{HCC}$, hepatocellular carcinoma; $\mathrm{HCV}$, hepatitis $\mathrm{C}$ virus; HOMA, homeostasis model assessment; IGF, insulin-like growth factor; IL, interleukin; IR, insulin receptor; IRS, insulin receptor substrate; MAPK, mitogen-activated protein kinase; mTORC, mammalian target of rapamycin complex; NAFLD, non-alcoholic fatty liver disease; NASH non-alcoholic steatohepatitis; PEPCK, phosphoenolpyruvate carboxykinase ; $\mathrm{PI3K}$, phosphatidylinositol 3-kinase; RR, relative risk; SOCS, suppressor of cytokine signalling; TG, triglycerides; TNF, tumour necrosis factor; VEGF, vascular endothelial growth factor.

\section{Conflict of interest: none}

Financial support: H.C has been supported by the Ministère de l'Education Nationale, de l'Enseignement Supérieur et de la Recherche and by Fondation ARC. C.D-M has received funding grants from Gefluc, Ligue Contre le Cancer (Comité de Paris) and Institut National du Cancer (INCa-DGOS_5790). 


\section{Key points:}

- Hyperinsulinemia compensatory to insulin resistance is common in the course of chronic liver diseases, irrespective of etiology.

- Insulinemia is an independent risk factor for HCC.

- In NAFLD, clinical and experimental evidence reveal that hepatic insulin resistance is partial; some pathways remain insulin-sensitive.

- HCC tumors exhibit major dysregulations in insulin-dependent pathways. 


\section{Abstract}

Hepatocellular carcinoma $(\mathrm{HCC})$ is the fifth most prevalent cancer and is one of the leading causes of cancer-related death. The risk factors for HCC include cirrhosis, chronic viral hepatitis, heavy alcohol intake and metabolic diseases such as obesity, type 2 diabetes and metabolic syndrome. Insulin resistance is a common denominator of all of these conditions and is tethered to hyperinsulinemia. Here, we give an overview of the recent advances linking hyperinsulinemia to HCC development and progression. In particular, we summarize the underlying causes of hyperinsulinemia in the setting of chronic liver diseases. We present epidemiological evidence linking metabolic diseases to HCC risk and HCC-related mortality, as well as the pathogenic cellular and molecular mechanisms explaining this relation. A better understanding of the mechanisms by which insulin participates in HCC biology might ultimately provide novel opportunities for prevention and treatment. 


\section{Introduction}

Hepatocellular carcinoma ( $\mathrm{HCC}$ ) is a primary malignancy of the liver arising from mature hepatocytes or hepatic progenitors. HCC is the fifth most common cancer worldwide, with more than 800,000 new cases annually and the second cause of cancer deaths. HCC is overwhelmingly related to chronic liver diseases (CLDs) associated with persistent inflammation, fibrosis and cirrhosis. Development of HCC in the cirrhotic liver is a stepwise process, which follows a dysplasia-carcinoma sequence that takes several decades to evolve. Chronic hepatitis B (HBV) and C $(\mathrm{HCV})$ virus infections are the leading risk factors of $\mathrm{HCC}$ worldwide, especially in Southeast Asia and Sub-Saharan Africa. In the US and Western countries where HCC incidence is rapidly rising, alcoholic cirrhosis and non-alcoholic fatty liver disease (NAFLD) are also important risk factors. HCC is a tumour with poor outcomes and limited therapeutic options (reviewed in [1-3]).

The liver plays a crucial role in the control of glucose metabolism by insulin and CLDs - irrespective of etiology - are prone to be associated with hepatic insulin resistance. Insulin resistance is defined as a refractory state of the liver to the negative regulatory effect of insulin on glucose production. Rise in circulating insulin levels is frequently associated with CLDs, resulting both from the impairment of hepatic insulin degradation and from the activation of insulin secretion by pancreatic beta-cells, a compensatory mechanism allowing to maintain euglycaemia in the early course of insulin resistant states. The relationship linking hyperinsulinemia and HCC is also bi-directional. Indeed, hyperinsulinemia resulting from insulin resistance, is a key feature of obesity and type 2 diabetes, which have emerged as important contributing diseases to HCC these last years. These metabolic diseases are closely associated to the development of non-alcoholic steatohepatitis (NASH), a severe 
form of NAFLD defined histologically as the coexistence of hepatic fat accumulation and inflammatory changes and which is a risk factor of HCC (reviewed in [3-5]).

Apart from diabetes, which is a risk factor for several cancers, prospective epidemiological studies have identified high circulating endogenous levels of insulin in non-diabetic subjects, as a strong and independent risk factor for the development of solid tumours such as breast, colorectal and pancreatic cancers [6-8]. In addition, hyperinsulinemia has been associated with more aggressive cancer phenotypes and poor prognosis [9-12]. As the prevalence of obesity and diabetes has dramatically increased worldwide during the last decades, cancers associated with hyperinsulinemia may drastically increase in the coming years.

Accumulating evidence suggests that there is a causative link between hyperinsulinemia and HCC development and progression. While the activation of insulin-dependent signalling pathways is certainly not sufficient to initiate tumorigenesis on its own, hepatocytes may develop adaptative insulin-dependent mechanisms to proliferate and survive during CLDs, which may in turn promote premalignant transformation and tumour growth. In addition, insulin may foster a microenvironment milieu favourable to the propagation of premalignant and malignant cells.

This review aims at summarizing key evidence linking hyperinsulinemia and insulin-dependent signalling pathways to the pathogenesis and the progression of HCC. We present recent epidemiological and clinical evidence supporting this association. We also delineate the potential underlying mechanisms by highlighting studies derived from human liver tissues and murine models. 


\section{Physiological insulin signalling in the hepatocyte}

Insulin is a major anabolic hormone produced by the pancreas primarily in response to glycemia elevations. Insulin plays a central role in the postprandial storage and utilisation of nutrients from food intake by regulating metabolism of carbohydrates, lipids and proteins in liver, skeletal muscle and adipose tissue. In the liver, insulin acts on hepatocytes to inhibit gluconeogenesis and to stimulate glycolysis, glucose storage as glycogen, protein synthesis and lipogenesis (reviewed in [13]). Insulin also induces cell swelling in hepatocytes that is critical for the stimulation of glycogen and protein synthesis [14]. Apart from its metabolic effects, insulin is also a prominent growth factor for hepatocytes favouring their division through the $G_{1} / S$ and $G_{2} / M$ transitions and their survival. Insulin also controls late mitosis progression and terminal differentiation in hepatocytes by regulating cytokinesis and tetrapolyploidization [15].

Insulin mediates its biological effects through binding to a heterotetrameric $\alpha_{2} \beta_{2}$ receptor tyrosine kinase expressed at the plasma membrane of hepatocytes. Two isoforms of insulin receptor (IR) arise from alternative splicing of IR pre-mRNA, resulting from inclusion (isoform IR-B) or skipping (isoform IR-A) of exon 11 encoding 12 amino acids located at the carboxyl-terminus of the extracellular a-subunit. IR premRNA splicing is developmentally regulated and IR-A is predominantly expressed in embryo and fetal tissues including the fetal liver [16]. IR-A becomes less expressed as differentiation progresses and adult hepatocytes exclusively express the IR-B isoform. Binding of insulin to IR-B leads to receptor tyrosine autophosphorylation and tyrosine phosphorylation of cytosolic substrates (including insulin receptor substrate (IRS)-1, IRS-2 and the adapter protein Shc), which activate a complex network of intracellular pathways including the two well-studied phosphatidylinositol 3-kinase 
(PI3K)-AKT and Ras/mitogen-activated protein kinase (MAPK) pathways (reviewed in [17]) (Figure 1). AKT (also known as protein kinase B) is central for the ability of insulin to regulate metabolism and multiple targets of AKT are involved in insulin action. Insulin stimulation of AKT activity through 3-phosphoinositide-dependent protein kinase 1 (PDK-1) and mammalian target of rapamycin complex 2 (mTORC2)dependent-mechanisms leads to the inhibitory phosphorylation of the transcription factor Forkhead box $O 1$ (FOXO1). This results in the blockage of FOXO1 transcriptional activity on gluconeogenic genes such as those encoding phosphoenolpyruvate carboxykinase (PEPCK) and glucose 6-phosphatase catalytic subunit (G6PC). The ability of insulin to stimulate hepatic lipogenesis in the liver depends upon the induction of the transcription factor sterol regulatory elementbinding protein 1c (SREBP-1c), which involves AKT- and mTORC1-dependent mechanisms. Interestingly, an insulin-stimulated non-canonical AKT-independent pathway involved in the regulation of hepatic glucose production has recently been identified by Lu and colleagues in triple AKT1/AKT2/FOXO1 knock-out mice [18].

\section{Chronic liver diseases, insulin resistance and compensatory hyperinsulinemia}

The liver plays a pivotal role in the control of glucose metabolism by insulin. Therefore, CLDs, which impair hepatic functions are frequently associated with changes in carbohydrate metabolism. In the diseased liver, insulin has a decreased ability to suppress hepatic gluconeogenesis and hepatic insulin degradation is impaired. Both mechanisms favor hyperinsulinemia, which initially compensates insulin resistance, but gradually associates with hyperglycemia. It is commonly accepted that insulin resistance is a key contributing factor to the pathogenesis and progression of CLDs (Figure 2). 
Cirrhosis. Cirrhosis consists in a fibrotic nodular transformation of the liver and is a long-term consequence of many different CLDs such as viral hepatitis, iron overload disease, NAFLD and alcohol abuse. Cirrhosis reduces the mass of functional hepatocytes and leads to portosystemic shunting. Whatever its underlying cause, cirrhosis predisposes to $\mathrm{HCC}$ and is considered as a preneoplasic condition. The vast majority of HCC worldwide develops in patients with pre-existing cirrhosis [19]. Cirrhosis is also a diabetogenic condition and diabetes mellitus secondary to cirrhosis is sometimes referred to as " hepatogenous diabetes ». The prevalence of insulin resistance, hyperinsulinemia and glucose intolerance among patients with cirrhosis is by far higher than in subjects without liver diseases. Sixty to eighty percent of patients with cirrhosis display hyperinsulinemia and/or glucose tolerance abnormalities and up to $20 \%$ develop overt diabetes. In addition, insulin resistance is an established risk factor for disease progression and reduced survival in patients with cirrhosis (reviewed in [20]). Hyperinsulinemia associated with cirrhosis could be linked not only to increased insulin secretion from pancreatic islets but also to a decreased hepatic clearance of insulin [21]. The liver is the main tissue involved in the clearance of circulating insulin. Plasma insulin half-life is 4-6 minutes and nearly $70 \%$ of the portovenous insulin is removed from the circulation after the first passage through the liver [22]. Due to portosystemic shunting, reduced hepatic function and exacerbated hepatocellular insulin resistance, insulin clearance from the circulation that occurs mainly via receptor-mediated endocytosis, is reduced in patients with cirrhosis.

$\mathrm{HCV}$ infection. Chronic HCV infection is associated with the highest HCC incidence in persons with cirrhosis (4-5\% yearly cumulative incidence [19, 23]). Epidemiological studies have suggested a link between HCV infection and diabetes, implying 
hepatitis $\mathrm{C}$ as a metabolic disease. Patients with chronic HCV infection are at greater risk of developing insulin resistance and diabetes at early stage of liver disease, even in the absence of hepatic fibrosis compared with non-infected individuals or patients with HBV infection (RR: $\sim 1.7$; reviewed in [24, 25]). The ex vivo analysis of liver biopsies from HCV patients, the transfection of HCC cell lines with HCV core proteins and the use of transgenic mice expressing $\mathrm{HCV}$ core proteins have revealed that HCV core proteins can directly interfere with hepatocyte intracellular insulin signalling. HCV core proteins promote inhibitory phosphorylation of IRS on serine residues and IRS proteasomal degradation through the up-regulation of suppressor of cytokine signalling-3 (SOCS-3) [26-29]. HCV infection may also favour insulin resistance through indirect mechanisms involving the production of proinflammatory cytokines such as tumour necrosis factor- $\alpha$ (TNF- $\alpha$ ) and interleukin-6 (IL-6) together with steatosis (an accumulation of triglycerides (TG) as fat droplets within the cytoplasm of hepatocytes) and mitochondrial dysfunction, all factors contributing to alter insulin signalling $[25,30]$.

Nevertheless, the concept of $\mathrm{HCV}$ as a diabetogenic virus per se has been challenged recently by Everhart and colleagues [31]. These authors did not find any association between HCV infection and diabetes or insulin resistance in a large U.S population of 15,128 adults. Rather, they identified a link between elevated liver enzymes and diabetes/insulin resistance, regardless of the HCV status. This suggests that the severity of the underlying liver disease is a confounding factor that may have been underestimated in previous studies.

NAFLD. NAFLD is a spectrum of liver abnormalities ranging from simple and benign steatosis to $\mathrm{NASH}$, a steatohepatitis that includes necroinflammation changes and variable degrees of fibrosis in the absence of alcohol abuse. NAFLD is considered to 
be the hepatic manifestation of metabolic diseases and is related to the presence of obesity, diabetes and metabolic syndrome. Ectopic lipid accumulation in the liver develops when the rate of hepatic TG synthesis (via increased fatty acid uptake and esterification into TG and de novo synthesis) exceeds the rate of TG catabolism (via $\beta$-oxidation of fatty acids and export as very low density lipoproteins). It is estimated that up to $70 \%$ of patients with type 2 diabetes and up to $90 \%$ of obese patients have some degree of fatty liver disease. Approximatively $20 \%$ of all cases of NAFLD present as steatohepatitis (reviewed in $[3,5,32]$. The exact prevalence of HCC in patients with NASH-related cirrhosis remains unknown. A study from the US found that the yearly cumulative incidence of $\mathrm{HCC}$ is $2.6 \%$ in patients with NASH-related cirrhosis, compared with $4.0 \%$ in patients with HCV-driven cirrhosis [23]. It has been reported that a significant number of patients with NAFLD-related HCC (more than one third) have no extensive fibrosis at presentation (reviewed in [5]). This suggests that the chronological sequence fibrosis/cirrhosis/HCC is not the sole carcinogenic pathway in the setting of NAFLD. Metabolic dysregulations observed during NASH could play an important role in promoting HCC.

Insulin resistance and hyperinsulinemia are the most common metabolic features of NAFLD. Hyperinsulinemia in NAFLD correlates with impaired hepatic clearance of insulin [33]. The pathophysiological mechanisms of insulin resistance in the setting of NAFLD are multifactorial and have been reviewed recently $[3,30,34$, 35]. Briefly, they include low-grade systemic inflammation (via the release of proinflammatory cytokines such as TNF- $\alpha$ and IL-6), imbalance in adipokine secretion, lipotoxicity (i.e. cellular dysfunctions linked to the accumulation of lipid intermediates such as diacylglycerols), modifications in the gut microbiota, mitochondrial defects and oxidative stress. These mechanisms contribute to impair insulin signalling at 
receptor and post-receptor levels by activating a variety of serine/threonine kinases (including c-Jun amino-terminal kinase, inhibitor kB kinase- $\beta$, conventional and novel protein kinases $\mathrm{C}, \mathrm{mTORC} 1 / \mathrm{S} 6$ kinase and MAPKs which promote inhibitory phosphorylation of IR and of its main substrates IRS-1 and IRS-2). The activation of transmembrane and cytosolic phosphoprotein phosphatases which are negative regulators of insulin action such as PP2A, PTP1B and SHP2 has also been reported in insulin resistant states (reviewed in [17, 36]). Proinflammatory cytokines contribute to cellular insulin resistance by inducing the expression of SOCS-1 and -3 proteins which prevent IRS-1 and IRS-2 tyrosine phosphorylation and/or promote IRS degradation (reviewed in [24, 37]).

\section{Epidemiological evidence linking diabetes, obesity and metabolic syndrome to HCC development and progression}

Diabetes, obesity and metabolic syndrome have been repeatedly associated with increased incidence for several cancers. Substantial epidemiological evidence has revealed that the incidence and prognosis of $\mathrm{HCC}$ are also significantly affected by these conditions, supporting a physiopathological link - probably through NAFLD between metabolic factors and liver cancer.

Type 2 diabetes. A positive association between diabetes and HCC has been reported in multiple observational studies from Asia, Europe and North America, independently of the cause underlying cirrhosis and/or CLD. Recent meta-analyses conducted from prospective studies concluded that the diabetic status is associated with a more than two-fold higher risk of HCC [38-40]. A prospective study based on the European Prospective Investigation into Cancer and Nutrition (EPIC) cohort (363,426 apparently healthy men and women recruited from 10 European countries 
between 1992 and 2000 ; mean follow-up time of 8.5 years) also supports this conclusion [41]. Moreover, the prospective analysis of a U.S. cohort including over one million subjects enrolled in the Cancer Prevention Study-II from 1982 to 2008 revealed that diabetes is associated with a higher risk of death from HCC (RR: 1.40; 95\% Cl [1.05-1.86]) [42]. The association between diabetes and HCC was linked with diabetes duration in some [43, 44] but not all studies [41, 45, 46]. There is a synergistic interaction between diabetes and other HCC risk factors such as virus and alcohol [47-49]. In addition, diabetes worsens HCC prognosis and impacts the surgical outcome of patients with cirrhosis after liver resection and transplantation [50].

Obesity. Obesity (defined as body mass index $(\mathrm{BMI}) \geq 30 \mathrm{~kg} / \mathrm{m}^{2}$ ) is a well-known risk factor for insulin resistance. Obesity, independently of type 2 diabetes, is implicated in initiation and progression of cancer at multiple sites including the liver $[51,52]$. Thus, in a recent meta-analysis of 26 prospective studies conducted in Europe, US and Asia (25,337 HCC cases published between 1994 and 2011), it has been shown that the risk of $\mathrm{HCC}$ is about twice higher among obese patients - specially males than in normal-weight individuals (RR: 1.83; 95\% Cl: 1.59-2.11) [53]. This positive association is independent of history of diabetes, viral infections and alcohol abuse. A prospective study based on the EPIC cohort confirmed the association between obesity - specially abdominal obesity, more specifically linked to insulin resistance and risk of HCC [54]. Obesity is also the leading risk factor of HCC-related cancer deaths in middle-aged men in the USA. Thus, a large prospective study conducted in more than 900,000 US citizens followed up for 16 years reported that in obese patients, the risk of mortality from HCC was much higher (RR: $4.52,95 \% \mathrm{Cl}: 2.94-$ 6.94 for men; RR: $1.68,95 \% \mathrm{Cl}: 0.93-3.05$ for women) than that from other cancers 
[55]. Obesity also increases the risk of HCC in populations already at high risk such as those with cirrhosis and viral hepatitis $[48,56,57]$. Obesity predicts a poor outcome after surgery and doubles HCC recurrence [58, 59].

Metabolic syndrome. The metabolic syndrome is a condition related to insulin resistance, defined as the association of central obesity with two or more other cardiovascular and/or diabetes risk factors including increased levels of plasma TG or glucose, reduced HDL-cholesterol and raised blood pressure [60]. In agreement with data on diabetes and obesity, a recent meta-analysis of 10 case series and Iongitudinal studies published through October 2011 concluded that the presence of metabolic syndrome is associated with the occurrence of liver cancer in men (RR: 1.43, 95\% Cl: 1.23-1.65) [61]. Two more recent studies performed on 3,649 HCC cases in the US confirmed that a pre-existing metabolic syndrome confers a statistically increased risk for HCC that is independent of other risk factors (RR: 2.13, 95\% Cl: 1.96-2.31 [62]; RR: 1.97, 95\% Cl: 1.03-3.79 [63]).

The increased amount of fat by itself is unlikely to be the only factor linking obesity to insulin resistance in metabolic syndrome. Several studies have shown that the limitation of adipose tissue expandability is a major driving factor of insulin resistance and inflammation (reviewed in [64]). Adipose tissue expansion is altered as a result of intrinsic limits in preadipocyte formation (mainly due to genetic factors and/or aging) and/or from altered maintenance of mature adipocytes (linked to fat inflammation or fibrosis among other factors). This increases lipid flux and induces ectopic lipid deposition in the liver. In addition, in the metabolic syndrome, the predominant enlargement of intra-abdominal fat, which is physiologically more insulin resistant than subcutaneous fat, further favours increased lipolysis and exposition of the liver to free fatty acids and pro-inflammatory cytokines. 
Insulin resistance markers, homeostasis model assessment (HOMA) index and plasma insulin levels, are predictors of HCC occurrence

As insulin resistance is a common metabolic disorder occuring in obesity, diabetes and metabolic syndrome, it is suspected that hyperinsulinemia is related to HCC. In favor, the HOMA index, a marker of insulin resistance which integrates both fasting glycemia and insulinemia, has been shown to be predictive of HCC occurrence and liver-related death or tranplantation in HCV patients with cirrhosis, independently of BMI [65-67]. Elevated fasting insulin, which is inversely related to insulin sensitivity, has been shown to be an independent risk factor for HCC in a prospective cohort of 2,903 male HBV carriers from Taiwan [68]. More recently, baseline serum levels of C-peptide (released from pro-insulin during beta-cell insulin secretion) have been found to be associated with a higher risk of $\mathrm{HCC}$ in the general population issued from the prospective EPIC cohort, independently of obesity parameters and other established liver cancer risk factors [69].

\section{Diabetes treatments and their impact on HCC development}

Several observational studies have suggested that some anti-diabetic medications could modify the risk of HCC in patients with diabetes mellitus. Two recent metaanalyses concluded that the biguanide metformin, which is the first-line drug for the treatment of type 2 diabetes, is associated with a diminished risk of HCC among patients with diabetes [70,71]. Metformin exerts its antidiabetic effects mostly by decreasing hepatic gluconeogenesis, resulting in reduced circulating glucose and insulin concentrations. Insulin-sensitizing effect of metformin could play an important role in reducing the risk of HCC. The preventive effect of metformin on HCC could 
also be related to its ability to directly act on tumour cells by promoting growth inhibition, apoptosis and senescence through the activation of 5-adenosine monophosphate-activated protein kinase (AMPK) and the subsequent inhibition of mTORC1 [71, 72]. Studies regarding the potential association between the use of insulin, insulin analogues such as insulin glargine or insulin secretagogues such as sulfonylureas and cancer risk have been controversially discussed [73, 74]. Although no definitive conclusions can be drawn, it seems clear that these drugs have no protective effect on HCC development in patients with diabetes $[41,75,76]$.

\section{The concept of selective insulin resistance in the liver}

Because insulin resistance is a major feature of CLDs at risk for $\mathrm{HCC}$, linking the activation of insulin pathways through hyperinsulinemia to liver carcinogenesis may seem counterintuitive. One potential hypothesis would be that hepatic insulin resistance is partial and that some pathways remain insulin-sensitive when they are exposed to higher than normal levels of insulin. During CLDs, hepatocytes that have escaped apoptosis and necrosis are exposed to intense selection pressure imposed by inflammation, hyperglycemia, oxidative stress and high circulating levels of free fatty acids, which probably drive cell transformation. The maintenance of some insulin signalling pathways could provide selective advantages for premalignant hepatocytes in terms of metabolism, proliferation and survival.

The concept of selective insulin resistance stems from the fact that, in common insulin-resistant states as observed in type 2 diabetes and obesity, hepatic lipogenesis and lipid production, physiologically activated by insulin, are increased and associated with liver steatosis. Paradoxically, this occurs in concert with increased glucose production, physiologically subjected to insulin-mediated negative 
regulation $[77,78]$. This concept is highly conceivable because of the complex nature of insulin signalling at the molecular level [17].

Using genetically engineered mice models of insulin resistance, the inability of hyperinsulinemia to suppress hepatic glucose production has been linked to the inability of insulin to inactivate the transcription factor FOXO1 through AKT2dependent phosphorylation $[79,80]$. Consistently, the activity of FOXO1 as well as the mRNA levels of two of its targets, the gluconeogenic genes PEPCK and G6PC, have been reported to increase progressively with the severity of the disease in liver biopsies from patients with NAFLD [81]. Otherwise, IR activation seems to play a crucial role in the establishment of liver steatosis during insulin-resistant states since mice with hepatocyte-specific deletion of IR exhibit marked insulin resistance but lack hepatic steatosis under high-fat diet [82, 83]. Similarly, the hepatic knockdown of IR with chemically-modified antisense oligonucleotides blocks the development of liver steatosis in genetically obese mice [83]. Moreover, humans with inactivating mutations in the IR are extremely insulin-resistant but do not show increased levels of de novo lipogenesis and do not develop hepatic steatosis [84]. Downstream of the IR, AKT2 is also required for hepatic lipid accumulation in murine models of obesity and insulin resistance induced by either leptin deficiency or high-fat diet feeding [85]. The failure of insulin to suppress gluconeogenesis while lipogenesis remains activated could be related to the fact that these two pathways are molecularly distinct and display differential sensitivity to the hormone, the lipogenic pathway being less affected by the reduced activation of IR/PI3K/AKT. In this setting, it appears that mTORC1, which is overactivated in the liver from obese rats [86] lies at a bifurcation of insulin signalling pathways upstream of lipogenesis and gluconeogenesis: mTORC1 inhibition blocks insulin-induced upregulation of lipogenic gene expression 
but does not affect insulin-mediated suppression of gluconeogenic gene expression [87].

In liver tissue from NAFLD patients, the upregulation of active FOXO1 is correlated to increased expression of IRS-2, increased activation of AKT2 and upregulation of the lipogenic transcription factor SREBP-1c [88, 89]. As FOXO1 has been identified as a positive regulator of IRS-2 expression in murine experimental models [90,91], it has been proposed that the upregulation of IRS-2 expression and AKT activity by unrestricted FOXO1 activity could represent a permissive mechanism linking hyperinsulinemia with the induction of lipogenesis during NAFLD [89].

PTEN (phosphatase and tensin homolog), a negative regulator of the PI3K/AKT pathway, which dephosphorylates the lipid second messenger phosphatidylinositol 3,4,5-triphosphate $\left(\mathrm{PIP}_{3}\right)$, is downregulated in obese patients, insulin-resistant patients and humans with liver steatosis [92]. Liver-specific Pten knockout mice display enhanced steatosis and develop HCC [93, 94]. The downregulation of PTEN could participate to the maintenance of some insulin signalling pathways. Interestingly, insulin has been recently identified as a negative regulator of PTEN expression in Caenorhabditis elegans and human breast cancer cells [95]. Whether or not this mechanism occurs in the setting of hyperinsulinemia associated to CLDs remains to be demonstrated. Increased activation of atypical protein kinases $\mathrm{C}$ has been also reported in the liver from obese rodents that could explain the effectiveness of hyperinsulinemia to stimulate certain pathways in the liver [96].

\section{Overactivation of insulin-dependent signalling pathways in human HCC}


Human HCC tumours have been characterized with respect to insulin signalling and it appears that this pathway is frequently altered and upregulated in a substantial number of cases due to the overexpression of signalling components and the loss of negative regulators. As a consequence, hyperinsulinemia may affect HCC development and progression directly by promoting metabolism, proliferation and survival of cancer cells (Fig. 2).

Quantitative and qualitative changes at the IR level. We have recently reported that IR is significantly overexpressed in $40 \%$ of $85 \mathrm{HCC}$ tumours analysed compared to adjacent nontumour tissue [97]. This increase is accompanied by a major modification of the relative expression of the two IR isoforms in $\approx 70 \%$ of $\mathrm{HCC}$ samples. The expression of IR-A (-exon 11) is induced while the expression of IR-B (+exon 11) is decreased irrespective of CLD etiology, suggesting that the increase of IR-A/IR-B ratio is a general mechanism of liver oncogenesis. We have demonstrated that the tumoral IR-B to IR-A shift results from the deregulation of IR pre-mRNA alternative splicing that is consecutive to the induction of RNA splicing factors expression from CELF, hnRNP and SF2/ASF families by the epidermal growth factor receptor (EGFR) pathway [97]. IR-A displays approximately 1.8-fold higher affinity for insulin than IR-B and is particularly active in mitogenic signalling in a variety of cancer cells including HCC [97, 98]. It has been reported that IR-A binds also proinsulin with high affinity, which stimulates proliferation in breast cancer cell lines [99]. Proinsulin is present at high levels in the plasma from insulin resistant patients and has been considered until now as a prohormone with little biological activity and no relevance to cancer biology. In view of these new data, proinsulin may play a biological role via IR-A activation during cancer development in a context of insulinresistance. IR-A is also a receptor for insulin-like growth factor-II (IGF-II), a growth 
peptide produced by the fetal liver and early after birth, which is re-expressed in some HCC tumours (reviewed in [100]). How these different ligands participate to $\mathrm{HCC}$ cell biology via IR-A activation deserves further investigation.

Upregulation of IRS expression. The expression of IRS-1 and IRS-2 (at both mRNA and protein levels) is frequently increased in $\mathrm{HCC}$ tumours compared to adjacent nontumour liver tissue [101-103]. IRS overexpression has been reported at early stages of liver carcinogenesis in preneoplastic lesions where it may amplify insulin signalling. IRS-1 overexpression is not sufficient to transform murine hepatocytes but it synergizes with the HBx viral protein to promote cellular dysplasia (see below) [104]. In patients with HCC, IRS-1 overexpression correlates with tumour size and tumour progression [101].

Loss of negative regulators of insulin signalling. As mentioned above, CLDs are associated with the up-regulation of SOCS proteins, which act at different levels to inhibit insulin signalling in the liver (reviewed in [24, 37]). Aberrant promoter methylation of SOCS has been frequently identified in HCC in comparison with adjacent nontumour liver tissue $[105,106]$. PTEN expression is frequently reduced in human HCC, and is associated with a poor prognosis [107].

Exacerbated lipogenesis. Metabolic changes are key early events during cellular transformation as the synthesis of new membranes and of specific lipids is essential for cancer cell growth and survival. It has been reported that the expression of key lipogenic enzymes and transcription factors is progressively induced from nontumoral liver tissue towards $\mathrm{HCC}$ and that aberrant lipogenesis correlates with clinical aggressiveness and poor survival [108-110]. The exacerbation of lipogenesis is essential for insulin signalling in HCC cells. Indeed, the abrogation of lipid synthesis through the silencing of lipogenic enzymes (fatty acid synthase, acetyl-coenzyme A 
carboxylase, stearoyl-CoA desaturase 1) or lipogenic transcription factors (SREBP1c) with RNA interference reduces insulin-dependent proliferation and survival in HCC cell lines [109, 111].

Warburg effect. A metabolic remodeling, shifting mitochondrial respiration to predominant cytosolic glycolysis called Warburg effect has been involved in the early stages of hepatocyte transformation. Upregulation of the glycolytic enzymes pyruvate kinase M2 (PKM2), hexokinase 2 and lactate deshydrogenase and inhibition of mitochondrial biogenesis and functions, increase insulin-activated glucose metabolism, providing a metabolic advantage for HCC cell growth [112, 113].

\section{Indirect effets of hyperinsulinemia}

Hyperinsulinemia may affect liver cancer development and progression not only through direct effets on the growth of preneoplastic and transformed hepatocytes but also indirectly by increasing the production of cytokines and mitogens, enhancing fibrosis and promoting angiogenesis (Figure 2).

IGF-I/IGFBP pathway. IGF-I is a mitogen that is primarily produced in the liver and shares sequence homology with insulin. IGF-I has a role in cancer development and high serum IGF-1 levels are associated with an increased risk of cancers such as colon and breast cancers (reviewed in [114]). Chronic hyperinsulinemia may lead to increase circulating levels of free and bioactive IGF-I because i) insulin stimulates growth hormone receptor expression which controls IGF-I production and secretion in the liver and ii) insulin decreases the hepatic synthesis and blood levels of IGFbinding proteins (IGFBP)-1 and -2 (reviewed in [115]). In the setting of CLDs, it is plausible that chronic elevation of insulinemia increases levels of IGF-I at early but not advanced stage of diseases. Indeed, IGF-I serum levels have been found to 
decrease gradually when compared between healthy subjects, patients with cirrhosis and patients with HCC (reviewed in [116]). A significant inverse association has been found between IGF-I and insulin levels in patients with HCC [117]. IGF-I deficiency in HCC is thought to result from the reduced synthesis capacity of the cirrhotic liver mass. In addition, some cytokines, including IL-1 $\beta$, TNF- $\alpha$ and IL- 6 , and miRNA such as miR-190b, which are elevated in patients with HCC have been reported to block IGF-I production in the liver [117].

Leptin. Leptin, the product of the $(o b)$ gene, is a pleiotropic adipokine best known as a regulator of food intake and energy expenditure via hypothalamic-mediated effects. Plasma leptin levels are abnormally high in obese patients and exhibit a positive correlation with the amount of fat mass and the degree of insulin resistance. Insulin regulates leptin availability by stimulating both leptin synthesis and the release of leptin from pre-existing intracellular pools in adipocytes and cancer cells $[118,119]$. The role of leptin during CLDs and liver carcinogenesis is complex (reviewed in [120, 121]). Leptin plays profibrogenic and proangiogenic roles by acting on hepatic stellate cells and Kupffer cells to synthetize extracellular matrix components, proinflammatory or proangiogenic cytokines [122-124]). Leptin promotes HCC cell proliferation, migration and invasion $[125,126]$. These data suggest that hyperinsulinemia could favour HCC development and progression through leptindependent mechanisms. However, leptin has also been shown to inhibit ectopic lipid storage, therefore limiting cellular lipotoxicity, in particular in the liver [127]. Consistently, leptin deficiency secondary to obesity with mutations in the ob gene, or to lipodystrophic syndromes due to genetically-determined reduced fat amount, is associated with severe insulin resistance and liver steatosis, which are reversed by leptin substitutive therapy [128]. 
Fibrosis. There is substantial evidence linking insulin resistance and fibrosis in patients with CLD. In HCV patients, the degree of insulin resistance parallels the liver fibrosis stage and insulin resistance is an independent predictor of fibrosis degree and progression [129-131]. Insulin resistance is also an independent predictor of advanced fibrosis in NAFLD [130]. The measurement of the liver stiffness, an accurate noninvasive diagnosis marker of liver fibrosis, is significantly correlated with HOMA-IR in NAFLD [132]. In a study of 782 patients with NAFLD, HOMA-IR was positively associated with advanced fibrosis (> stage 2) [133]. The link between insulin resistance and fibrosis could result from the ability of insulin to directly activate hepatic stellate cells which, as shown in vitro, leads to increased expression of key fibrotic proteins such as connective tissue growth factor and extracellular matrix production [134, 135]. As mentioned above, the ability of insulin to stimulate leptin expression could also play a contributing role in the hormonal promotion of liver fibrosis.

Angiogenesis. HCC is a highly vascularized tumour, relying on the formation of new blood vessels for growth. Vascular endothelial growth factor (VEGF) is critical in this process and anti-angiogenic therapies such as sorafenib possess a therapeutic potential in advanced HCC [136]. Insulin has been reported to directly stimulate vascular endothelial cell proliferation, migration and capillary tube formation in vitro and angiogenesis in animal models (reviewed in [137-139]). Insulin is also a potent upregulator of VEGF mRNA expression and VEGF release from adipocytes, vascular endothelial cells and cancer cell types, thus regulating neovascularization indirectly $[140,141]$. Insulin promotes sinusoidal endothelial cell proliferation through VEGF upregulation in regenerating rat liver after partial hepatectomy [142]. As mentioned above, insulin induction of leptin expression in adipocytes could also be an endocrine 
mechanism whereby insulin could promote angiogenesis. As angiogenesis is also essential to the metastatic dissemination of tumour cells to distant organs, insulin is expected to play a prominent role in this process. Accordingly, IR downregulation in breast cancer cell lines with short hairpin RNA reduces VEGF expression and cell metastatic potential after graft into the mammary fat pad of athymic mice [143]. Similarly, mammary tumour metastasis is significantly diminished in the absence of IRS (reviewed in [144]).

\section{Advances from animal models}

Because of the complex interaction between metabolic dysregulations and HCC, animal models have been helpful to dissect and increase the understanding of molecular links between hyperinsulinemia and HCC.

Intrahepatic transplantation of pancreatic islets in rats. Dombrowski and colleagues have developed two animal models of pancreatic islet transplantation into the liver of streptozotocin-induced diabetic rats and of genetically diabetic BB/Pfd rats [145-147]. In these models, as a low number of islets is transplanted, glycemia is not efficiently controled and a mild systemic hyperglycemia persists which constitutes a constant stimulus for the islet grafts to synthesize and secrete insulin. Strikingly, in the first three months after transplantation, morphological changes are observed in the liver acini located downstream of the islet graft, which are reminiscent of preneoplastic foci observed in chemically-induced liver carcinogenesis: excessive storage of glycogen and lipids combined with a high hepatocyte turnover. These lesions gradually expand into the liver and progress to HCC within 6 to 24 months. At the molecular level, the IR/IRS-1/AKT/mTOR pathway is markedly dysregulated together with fatty acid synthesis and glycolysis in the hepatocellular lesions [111, 147]. These 
models highlight that local hyperinsulinism in the rat liver triggers a number of metabolic alterations that are associated with preneoplastic foci and $\mathrm{HCC}$ occurrence.

IRS1-kockout mice. C57BL/6J mice submitted to long-term high fat diet become obese, insulin resistant, and successively develop steatosis, NASH and liver tumours. The knockdown of IRS-1 in this genetic background dramatically protects mice against high fat diet-induced NASH and liver tumourigenesis despite severe insulin resistance and hyperinsulinemia [148]. These findings suggest that the maintenance of hepatic insulin signalling pathways through IRS-1 is required for the development of NASH and $\mathrm{HCC}$ in the setting of insulin resistance and support the concept of selective insulin resistance during CLD.

IRS-1 overexpressing mice. Transgenic mice that constitutively overexpress IRS-1 in the liver never develop HCC indicating that overexpression of IRS-1 alone is not sufficient to cause hepatocellular transformation [149]. In contrast, combined overexpression of IRS-1 together with $\mathrm{HBx}$ viral protein has a synergistic effect to promote dysplasia and HCC through both IR/IRS-1/MAPK and Wnt/ß-catenin cascades [104].

AB6F1 mice. By intercrossing A/JCr with C57BL/6J mice, Hines and colleagues have identified male F1 offspring that develops spontaneous hyperinsulinemia, severe NAFLD by 9 months and HCC by 15 months on a standard chow diet in the absence of obesity or type 2 diabetes [150]. Hyperinsulinemia is associated with an adipogenic transition of hepatocytes involving the induction of expression of PKM2, an anabolic enzyme implicated in tumorigenesis and the Warburg effect [151]. This model of primary insulin resistance supports the hypothesis that hyperinsulinemia is a critical feature to promote the progression from NAFLD to HCC in mice. 


\section{Therapeutic targeting of IR signalling}

Several therapeutic strategies can be considered to reduce IR-dependent signalling in the course of CLD and HCC. As insulin has emerged as a new candidate biomarker to refine HCC risk assessment beyond established risk factors, medications that improve insulin resistance (such as metformin) deserve further investigation for $\mathrm{HCC}$ prevention.

IGF-II, a ligand for IR-A, is a potential therapeutic target in HCC. Thus the growth of human HCC cell lines is blocked in vitro and in vivo with DX-2647, a human monoclonal antibody against IGF-II [152]. BI 836845, a monoclonal antibody to IGF-II and MEDI-573, a dual-targeting monoclonal antibody to IGF-II/IGF-I are currently under clinical investigation for solid tumours including HCC (https://clinicaltrials.gov). This anti-ligand approach is of particular interest since it will result in inhibition of IR-A signalling without interfering with IR-B signalling.

To date, there is no available antibody blocking selectively IR-A. Several antibodies against the structurally related IGF-1R have been developed. These antibodies are highly specific to IGF-1R and spare IR. Unfortunately, the use of these antibodies is associated with a "metabolic toxicity", resulting in increased levels of growth hormone, IGF-I, insulin and glucose [114]; supraphysiological levels of IGF-I and insulin may lead to the adverse stimulation of IR. In addition, we have reported that the anti-IGF-1R antibody AVE1642 induced a compensatory resistance mechanism involving the EGFR/HER3 pathway In HCC cell lines [153]. A phase II study evaluating the anti-IGF-1R cixutumumab (IMC-A12) in unselected patients with advanced HCC did not show meaningful activity [154]. 
Due to the high homology between the catalytic domains of IGF-1R and IR, dual IGF-1R/IR tyrosine kinase inhibitors have been developed for clinical oncology. While hyperinsulinemia is likely in treated patients, these drugs have the potential to suppress any deleterious effects of insulin in cancer cells. A pre-clinical study shows that the IGF-1R/IR inhibitor OSI-906 is efficient in human HCC cell lines expressing high levels of IGF-II and IR [155]. Two phase II clinical trials testing a continuous dosing regimen of OSI-906 in patients with advanced $\mathrm{HCC}$ after failure of sorafenib or in combination with sorafenib have been stopped probably due to safety issues (https://clinicaltrials.gov). It seems that intermittent dosing regimen of OSI-906 should reduce toxicity [156]. 


\section{Concluding remarks}

- Insulin resistance and compensatory hyperinsulinemia are strikingly linked to CLDs, whatever their underlying cause. Clinical and epidemiological data together with studies in both humans and animal models of insulin resistance now suggest that high circulating concentrations of insulin per se are significantly associated with an increased risk of HCC, independently of established liver cancer risk factors and obesity parameters.

- These data have important implications for the clinical management of patients with CLD. Efforts to manage hyperinsulinemia should be considered in patients with any form of CLD. Due the increased burden of diabetes and obesity worldwide, these conditions would plausibly account for more NASH-related HCC cases in the future. Effective treatments of insulin resistance and hyperinsulinemia are likely to enhance liver cancer prevention and improve disease outcomes.

- It is highly probable that hyperinsulinemia collaborates with other environmental factors to induce multiple hits that are required for liver tumorigenesis and progression. Further research is needed to explore the relative importance of hyperinsulinemia in these processes. Elucidating the signalling pathways for HCC development in the setting of hyperinsulinemia will increase our understanding of the pathogenesis of $\mathrm{HCC}$ and might promote the development of novel preventive and therapeutic strategies. 


\section{Acknowledgements}

We are grateful to Dr F Praz for critical reading of the manuscript. 


\section{Legends to Figures}

\section{Figure 1: Insulin signalling in hepatocytes.}

Upon insulin binding, a conformational change and autophosphorylation of the insulin receptor (IR) occur leading to the recruitment and phosphorylation of IR substrates such as IRS-1, IRS-2 and Shc proteins and to the initiation of cascades of phosphorylation events. IRS proteins mostly activate the PI3K-Akt pathway by recruiting and activating $\mathrm{PI} 3 \mathrm{~K}$, leading to the generation of second messenger PIP3. Membrane-bound $\mathrm{PIP}_{3}$ recruits and activates PDK-1, which phosphorylates and activates Akt. Akt mediates most of insulin's metabolic effects, regulating glycogen, protein and lipid syntheses as well as gluconeogenesis. Akt also plays a role in the control of cell cycle and survival. The Shc-Grb2-Sos-Ras pathway rather controls cellular proliferation. For glucose metabolism, insulin increases the expression of glucokinase (GCK), the enzyme responsible for the first step of glycolysis. It suppresses the expression of the cytosolic form of phosphoenolpyruvate carboxykinase (PEPCK) and glucose 6-phosphatase catalytic subunit (G6PC), the first and last steps of gluconeogenesis, respectively. For lipid metabolism, insulin increases the expression level of sterol regulatory element-binding protein $1 \mathrm{c}$ (SREBP-1c), a transcription factor critical for fatty acid biosynthesis through the upregulation of the lipogenic enzymes acetyl-CoA carboxylase (ACC), fatty acid synthase (FASN) and stearoyl-CoA desaturase 1 (SCD1).

Figure 2: Pathogenic pathways that may link hyperinsulinemia to HCC development and progression. 


\section{References}

[1] El-Serag H B. Epidemiology of viral hepatitis and hepatocellular carcinoma. Gastroenterology 2012; 142: 1264-1273.

[2] Forner A, Llovet J M, Bruix J. Hepatocellular carcinoma. Lancet 2012; 379: $1245-1255$.

[3] Michelotti G A, Machado M V, Diehl A M. NAFLD, NASH and liver cancer. Nature reviews Gastroenterology \& hepatology 2013; 10: 656-665.

[4] Blonski W, Kotlyar D S, Forde K A. Non-viral causes of hepatocellular carcinoma. World J Gastroenterol 2010; 16: 3603-3615.

[5] Baffy G, Brunt E M, Caldwell S H. Hepatocellular carcinoma in non-alcoholic fatty liver disease: An emerging menace. J Hepatol 2012; 56: 1384-1391.

[6] Kabat G C, Kim M, Caan B J, Chlebowski R T, Gunter M J, Ho G Y, et al. Repeated measures of serum glucose and insulin in relation to postmenopausal breast cancer. Int J Cancer 2009; 125: 2704-2710.

[7] Gunter M J, Hoover D R, Yu H, Wassertheil-Smoller S, Rohan T E, Manson J $\mathrm{E}$, et al. Insulin, insulin-like growth factor-I, and risk of breast cancer in postmenopausal women. J Natl Cancer Inst 2009; 101: 48-60.

[8] Wolpin B M, Bao Y, Qian Z R, Wu C, Kraft P, Ogino S, et al. Hyperglycemia, insulin resistance, impaired pancreatic beta-cell function, and risk of pancreatic cancer. J Natl Cancer Inst 2013; 105: 1027-1035.

[9] Goodwin P J, Ennis M, Pritchard K I, Trudeau M E, Koo J, Madarnas Y, et al. Fasting insulin and outcome in early-stage breast cancer: results of a prospective cohort study. J Clin Oncol 2002; 20: 42-51. 
[10] Duggan C, Irwin M L, Xiao L, Henderson K D, Smith A W, Baumgartner R N, et al. Associations of insulin resistance and adiponectin with mortality in women with breast cancer. J Clin Oncol 2011; 29: 32-39.

[11] Irwin M L, Duggan C, Wang C Y, Smith A W, Mctiernan A, Baumgartner R N, et al. Fasting C-peptide levels and death resulting from all causes and breast cancer: the health, eating, activity, and lifestyle study. J Clin Oncol 2011; 29: 47-53.

[12] Dankner R, Shanik M H, Keinan-Boker L, Cohen C, Chetrit A. Effect of elevated basal insulin on cancer incidence and mortality in cancer incident patients: the Israel GOH 29-year follow-up study. Diabetes Care 2012; 35: 1538-1543.

[13] Cherrington A D, Moore M C, Sindelar D K, Edgerton D S. Insulin action on the liver in vivo. Biochemical Society transactions 2007; 35: 1171-1174.

[14] Reinehr R, Sommerfeld A, Haussinger D. Insulin induces swelling-dependent activation of the epidermal growth factor receptor in rat liver. J Biol Chem 2010; 285 : 25904-25912.

[15] Celton-Morizur S, Merlen G, Couton D, Margall-Ducos G, Desdouets C. The insulin/Akt pathway controls a specific cell division program that leads to generation of binucleated tetraploid liver cells in rodents. J Clin Invest 2009; 119: 1880-1887.

[16] Liang L, Guo W H, Esquiliano D R, Asai M, Rodriguez S, Giraud J, et al. Insulin-like growth factor 2 and the insulin receptor, but not insulin, regulate fetal hepatic glycogen synthesis. Endocrinology 2010; 151: 741-747.

[17] Boucher J, Kleinridders A, Kahn C R. Insulin receptor signaling in normal and insulin-resistant states. Cold Spring Harbor perspectives in biology 2014; 6 .

[18] Lu M, Wan M, Leavens K F, Chu Q, Monks B R, Fernandez S, et al. Insulin regulates liver metabolism in vivo in the absence of hepatic Akt and Foxo1. Nat Med 2012; 18: 388-395. 
[19] Fattovich G, Stroffolini T, Zagni I, Donato F. Hepatocellular carcinoma in cirrhosis: incidence and risk factors. Gastroenterology 2004; 127: S35-50.

[20] Garcia-Compean D, Jaquez-Quintana J O, Gonzalez-Gonzalez J A, Maldonado-Garza H. Liver cirrhosis and diabetes: risk factors, pathophysiology, clinical implications and management. World J Gastroenterol 2009; 15: 280-288.

[21] Letiexhe M R, Scheen A J, Gerard P L, Bastens B H, Pirotte J, Belaiche J, et al. Insulin secretion, clearance, and action on glucose metabolism in cirrhotic patients. J Clin Endocrinol Metab 1993; 77: 1263-1268.

[22] Duckworth W C, Bennett R G, Hamel F G. Insulin degradation: progress and potential. Endocr Rev 1998; 19: 608-624.

[23] Ascha M S, Hanouneh I A, Lopez R, Tamimi T A, Feldstein A F, Zein N N. The incidence and risk factors of hepatocellular carcinoma in patients with nonalcoholic steatohepatitis. Hepatology 2010; 51: 1972-1978.

[24] Douglas M W, George J. Molecular mechanisms of insulin resistance in chronic hepatitis C. World J Gastroenterol 2009; 15: 4356-4364.

[25] Mangia A, Ripoli M. Insulin resistance, steatosis and hepatitis C virus. Hepatology international 2013; 7: 782-789.

[26] Aytug S, Reich D, Sapiro L E, Bernstein D, Begum N. Impaired IRS-1/PI3kinase signaling in patients with HCV: a mechanism for increased prevalence of type 2 diabetes. Hepatology 2003; 38: 1384-1392.

[27] Kawaguchi T, Yoshida T, Harada M, Hisamoto T, Nagao Y, Ide T, et al. Hepatitis C virus down-regulates insulin receptor substrates 1 and 2 through upregulation of suppressor of cytokine signaling 3. Am J Pathol 2004; 165: 1499-1508. 
[28] Shintani Y, Fujie H, Miyoshi H, Tsutsumi T, Tsukamoto K, Kimura S, et al. Hepatitis C virus infection and diabetes: direct involvement of the virus in the development of insulin resistance. Gastroenterology 2004; 126: 840-848.

[29] Miyamoto H, Moriishi K, Moriya K, Murata S, Tanaka K, Suzuki T, et al. Involvement of the PA28gamma-dependent pathway in insulin resistance induced by hepatitis C virus core protein. J Virol 2007; 81: 1727-1735.

[30] Samuel V T, Shulman G I. Mechanisms for insulin resistance: common threads and missing links. Cell 2012; 148: 852-871.

[31] Ruhl C E, Menke A, Cowie C C, Everhart J E. The Relationship of Hepatitis C Virus Infection with Diabetes in the United States Population. Hepatology 2014; 60: 1139-1149.

[32] Siegel A B, Zhu A X. Metabolic syndrome and hepatocellular carcinoma: two growing epidemics with a potential link. Cancer 2009; 115: 5651-5661.

[33] Bril F, Lomonaco R, Orsak B, Ortiz-Lopez C, Webb A, Tio F, et al. Relationship between disease severity, hyperinsulinemia, and impaired insulin clearance in patients with nonalcoholic steatohepatitis. Hepatology 2014; 59: 21782187.

[34] Moschen A R, Kaser S, Tilg H. Non-alcoholic steatohepatitis: a microbiotadriven disease. Trends Endocrinol Metab 2013; 24: 537-545.

[35] Shulman G I. Ectopic fat in insulin resistance, dyslipidemia, and cardiometabolic disease. N Engl J Med 2014; 371: 2237-2238.

[36] Xu E, Schwab M, Marette A. Role of protein tyrosine phosphatases in the modulation of insulin signaling and their implication in the pathogenesis of obesitylinked insulin resistance. Reviews in endocrine \& metabolic disorders 2014; 15: 7997. 
[37] Galic S, Sachithanandan N, Kay T W, Steinberg G R. Suppressor of cytokine signalling (SOCS) proteins as guardians of inflammatory responses critical for regulating insulin sensitivity. Biochem J 2014; 461: 177-188.

[38] Wang P, Kang D, Cao W, Wang Y, Liu Z. Diabetes mellitus and risk of hepatocellular carcinoma: a systematic review and meta-analysis. Diabetes/metabolism research and reviews 2012; 28: 109-122.

[39] Yang W S, Va P, Bray F, Gao S, Gao J, Li H L, et al. The role of pre-existing diabetes mellitus on hepatocellular carcinoma occurrence and prognosis: a metaanalysis of prospective cohort studies. PLoS One 2011; 6: e27326.

[40] Wang C, Wang X, Gong G, Ben Q, Qiu W, Chen Y, et al. Increased risk of hepatocellular carcinoma in patients with diabetes mellitus: a systematic review and meta-analysis of cohort studies. Int J Cancer 2012; 130: 1639-1648.

[41] Schlesinger S, Aleksandrova K, Pischon T, Jenab M, Fedirko V, Trepo E, et al. Diabetes mellitus, insulin treatment, diabetes duration, and risk of biliary tract cancer and hepatocellular carcinoma in a European cohort. Ann Oncol 2013; 24: 2449-2455. [42] Campbell P T, Newton C C, Patel A V, Jacobs E J, Gapstur S M. Diabetes and cause-specific mortality in a prospective cohort of one million U.S. adults. Diabetes Care 2012; 35: 1835-1844.

[43] El-Serag H B, Tran T, Everhart J E. Diabetes increases the risk of chronic liver disease and hepatocellular carcinoma. Gastroenterology 2004; 126: 460-468.

[44] Hassan M M, Curley S A, Li D, Kaseb A, Davila M, Abdalla E K, et al. Association of diabetes duration and diabetes treatment with the risk of hepatocellular carcinoma. Cancer 2010; 116: 1938-1946. 
[45] Rousseau M C, Parent M E, Pollak M N, Siemiatycki J. Diabetes mellitus and cancer risk in a population-based case-control study among men from Montreal, Canada. Int J Cancer 2006; 118: 2105-2109.

[46] Atchison E A, Gridley G, Carreon J D, Leitzmann M F, Mcglynn K A. Risk of cancer in a large cohort of U.S. veterans with diabetes. Int J Cancer 2011; 128: 635643.

[47] Hassan M M, Hwang L Y, Hatten C J, Swaim M, Li D, Abbruzzese J L, et al. Risk factors for hepatocellular carcinoma: synergism of alcohol with viral hepatitis and diabetes mellitus. Hepatology 2002; 36: 1206-1213.

[48] Chen C L, Yang H I, Yang W S, Liu C J, Chen P J, You S L, et al. Metabolic factors and risk of hepatocellular carcinoma by chronic hepatitis B/C infection: a follow-up study in Taiwan. Gastroenterology 2008; 135: 111-121.

[49] Arase Y, Kobayashi M, Suzuki F, Suzuki Y, Kawamura Y, Akuta N, et al. Effect of type 2 diabetes on risk for malignancies includes hepatocellular carcinoma in chronic hepatitis C. Hepatology 2013; 57: 964-973.

[50] Wang Y G, Wang P, Wang B, Fu Z J, Zhao W J, Yan S L. Diabetes mellitus and poorer prognosis in hepatocellular carcinoma: a systematic review and metaanalysis. PLoS One 2014; 9: e95485.

[51] Aleman J O, Eusebi L H, Ricciardiello L, Patidar K, Sanyal A J, Holt P R. Mechanisms of obesity-induced gastrointestinal neoplasia. Gastroenterology 2014; 146: 357-373.

[52] Vanni E, Bugianesi E. Obesity and liver cancer. Clinics in liver disease 2014; 18: $191-203$. 
[53] Chen Y, Wang X, Wang J, Yan Z, Luo J. Excess body weight and the risk of primary liver cancer: an updated meta-analysis of prospective studies. Eur J Cancer 2012; 48: 2137-2145.

[54] Schlesinger S, Aleksandrova K, Pischon T, Fedirko V, Jenab M, Trepo E, et al. Abdominal obesity, weight gain during adulthood and risk of liver and biliary tract cancer in a European cohort. Int J Cancer 2013; 132: 645-657.

[55] Calle E E, Rodriguez C, Walker-Thurmond K, Thun M J. Overweight, obesity, and mortality from cancer in a prospectively studied cohort of U.S. adults. N Engl J Med 2003; 348: 1625-1638.

[56] Yu M W, Shih W L, Lin C L, Liu C J, Jian J W, Tsai K S, et al. Body-mass index and progression of hepatitis B: a population-based cohort study in men. J Clin Oncol 2008; 26: 5576-5582.

[57] Akiyama T, Mizuta T, Kawazoe S, Eguchi Y, Kawaguchi Y, Takahashi H, et al. Body mass index is associated with age-at-onset of HCV-infected hepatocellular carcinoma patients. World J Gastroenterol 2011; 17: 914-921.

[58] Nair S, Verma S, Thuluvath P J. Obesity and its effect on survival in patients undergoing orthotopic liver transplantation in the United States. Hepatology 2002; 35: 105-109.

[59] Mathur A, Franco E S, Leone J P, Osman-Mohamed H, Rojas H, Kemmer N, et al. Obesity portends increased morbidity and earlier recurrence following liver transplantation for hepatocellular carcinoma. HPB : the official journal of the International Hepato Pancreato Biliary Association 2013; 15: 504-510.

[60] Alberti K G, Zimmet P, Shaw J, Group I D F E T F C. The metabolic syndrome-a new worldwide definition. Lancet 2005; 366: 1059-1062. 
[61] Esposito K, Chiodini P, Colao A, Lenzi A, Giugliano D. Metabolic Syndrome and Risk of Cancer: A systematic review and meta-analysis. Diabetes Care 2012; 35: 2402-2411.

[62] Welzel T M, Graubard B I, Zeuzem S, El-Serag H B, Davila J A, Mcglynn K A. Metabolic syndrome increases the risk of primary liver cancer in the United States: A study in the SEER-medicare database. Hepatology 2011; 54: 463-471.

[63] Turati F, Talamini R, Pelucchi C, Polesel J, Franceschi S, Crispo A, et al. Metabolic syndrome and hepatocellular carcinoma risk. Br J Cancer 2013; 108: 222228.

[64] Virtue S, Vidal-Puig A. Adipose tissue expandability, lipotoxicity and the Metabolic Syndrome-an allostatic perspective. Biochim Biophys Acta 2010; 1801: 338-349.

[65] Nkontchou G, Bastard J P, Ziol M, Aout M, Cosson E, Ganne-Carrie N, et al. Insulin resistance, serum leptin, and adiponectin levels and outcomes of viral hepatitis C cirrhosis. J Hepatol 2010; 53: 827-833.

[66] Hung $\mathrm{C} \mathrm{H}$, Wang $\mathrm{J} \mathrm{H}$, Hu T H, Chen $\mathrm{CH}$, Chang $\mathrm{K} \mathrm{C}$, Yen $\mathrm{Y} \mathrm{H}$, et al. Insulin resistance is associated with hepatocellular carcinoma in chronic hepatitis C infection. World J Gastroenterol 2010; 16: 2265-2271.

[67] Salmon D, Bani-Sadr F, Loko M A, Stitou H, Gervais A, Durant J, et al. Insulin resistance is associated with a higher risk of hepatocellular carcinoma in cirrhotic HIV/HCV-co-infected patients: Results from ANRS CO13 HEPAVIH. J Hepatol 2012; 56: 862-868.

[68] Chao L T, Wu C F, Sung F Y, Lin C L, Liu C J, Huang C J, et al. Insulin, glucose and hepatocellular carcinoma risk in male hepatitis B carriers: results from 17-year follow-up of a population-based cohort. Carcinogenesis 2011; 32: 876-881. 
[69] Aleksandrova K, Boeing $H$, Nothlings U, Jenab M, Fedirko V, Kaaks R, et al. Inflammatory and metabolic biomarkers and risk of liver and bilary tract cancer. Hepatology 2014; 60: 858-871.

[70] Zhang H, Gao C, Fang L, Zhao H C, Yao S K. Metformin and reduced risk of hepatocellular carcinoma in diabetic patients: a meta-analysis. Scandinavian journal of gastroenterology $2013 ; 48: 78-87$.

[71] Chen H P, Shieh J J, Chang C C, Chen T T, Lin J T, Wu M S, et al. Metformin decreases hepatocellular carcinoma risk in a dose-dependent manner: populationbased and in vitro studies. Gut 2013; 62: 606-615.

[72] Zheng L, Yang W, Wu F, Wang C, Yu L, Tang L, et al. Prognostic significance of AMPK activation and therapeutic effects of metformin in hepatocellular carcinoma. Clin Cancer Res 2013; 19: 5372-5380.

[73] Karlstad O, Starup-Linde J, Vestergaard P, Hjellvik V, Bazelier M T, Schmidt M K, et al. Use of insulin and insulin analogs and risk of cancer - systematic review and meta-analysis of observational studies. Current drug safety 2013; 8: 333-348.

[74] Lutz S Z, Staiger H, Fritsche A, Haring H U. Antihyperglycaemic therapies and cancer risk. Diabetes \& vascular disease research : official journal of the International Society of Diabetes and Vascular Disease 2014; 11: 371-389.

[75] Carstensen B, Witte D R, Friis S. Cancer occurrence in Danish diabetic patients: duration and insulin effects. Diabetologia 2012; 55: 948-958.

[76] Chang C H, Lin J W, Wu L C, Lai M S, Chuang L M. Oral insulin secretagogues, insulin, and cancer risk in type 2 diabetes mellitus. J Clin Endocrinol Metab 2012; 97: E1170-1175.

[77] Brown M S, Goldstein J L. Selective versus total insulin resistance: a pathogenic paradox. Cell metabolism 2008; 7: 95-96. 
[78] Farese R V, Jr., Zechner R, Newgard C B, Walther T C. The problem of establishing relationships between hepatic steatosis and hepatic insulin resistance. Cell metabolism 2012; 15: 570-573.

[79] Matsumoto M, Pocai A, Rossetti L, Depinho R A, Accili D. Impaired regulation of hepatic glucose production in mice lacking the forkhead transcription factor Foxo1 in liver. Cell metabolism 2007; 6: 208-216.

[80] Dong X C, Copps K D, Guo S, Li Y, Kollipara R, Depinho R A, et al. Inactivation of hepatic Foxo1 by insulin signaling is required for adaptive nutrient homeostasis and endocrine growth regulation. Cell metabolism 2008; 8: 65-76.

[81] Valenti L, Rametta R, Dongiovanni P, Maggioni M, Fracanzani A L, Zappa M, et al. Increased expression and activity of the transcription factor FOXO1 in nonalcoholic steatohepatitis. Diabetes 2008; 57: 1355-1362.

[82] Biddinger S B, Hernandez-Ono A, Rask-Madsen C, Haas J T, Aleman J O, Suzuki R, et al. Hepatic insulin resistance is sufficient to produce dyslipidemia and susceptibility to atherosclerosis. Cell metabolism 2008; 7: 125-134.

[83] Haas J T, Miao J, Chanda D, Wang Y, Zhao E, Haas M E, et al. Hepatic insulin signaling is required for obesity-dependent expression of SREBP-1c mRNA but not for feeding-dependent expression. Cell metabolism 2012; 15: 873-884.

[84] Semple R K, Sleigh A, Murgatroyd P R, Adams C A, Bluck L, Jackson S, et al. Postreceptor insulin resistance contributes to human dyslipidemia and hepatic steatosis. J Clin Invest 2009; 119: 315-322.

[85] Leavens K F, Easton R M, Shulman G I, Previs S F, Birnbaum M J. Akt2 is required for hepatic lipid accumulation in models of insulin resistance. Cell metabolism 2009; 10: 405-418. 
[86] Khamzina L, Veilleux A, Bergeron S, Marette A. Increased activation of the mammalian target of rapamycin pathway in liver and skeletal muscle of obese rats: possible involvement in obesity-linked insulin resistance. Endocrinology 2005; 146 : $1473-1481$.

[87] Li S, Brown M S, Goldstein J L. Bifurcation of insulin signaling pathway in rat liver: $\mathrm{mTORC1}$ required for stimulation of lipogenesis, but not inhibition of gluconeogenesis. Proc Natl Acad Sci U S A 2010; 107: 3441-3446.

[88] Pettinelli $P$, Videla $L$ A. Up-regulation of PPAR-gamma mRNA expression in the liver of obese patients: an additional reinforcing lipogenic mechanism to SREBP1c induction. J Clin Endocrinol Metab 2011; 96: 1424-1430.

[89] Rametta R, Mozzi E, Dongiovanni P, Motta B M, Milano M, Roviaro G, et al. Increased insulin receptor substrate 2 expression is associated with steatohepatitis and altered lipid metabolism in obese subjects. International journal of obesity 2013; 37: $986-992$.

[90] Ide T, Shimano H, Yahagi N, Matsuzaka T, Nakakuki M, Yamamoto T, et al. SREBPs suppress IRS-2-mediated insulin signalling in the liver. Nature cell biology 2004; 6: 351-357.

[91] Qu S, Altomonte J, Perdomo G, He J, Fan Y, Kamagate A, et al. Aberrant Forkhead box $\mathrm{O} 1$ function is associated with impaired hepatic metabolism. Endocrinology 2006; 147: 5641-5652.

[92] Vinciguerra M, Veyrat-Durebex C, Moukil M A, Rubbia-Brandt L, RohnerJeanrenaud F, Foti M. PTEN down-regulation by unsaturated fatty acids triggers hepatic steatosis via an NF-kappaBp65/mTOR-dependent mechanism. Gastroenterology 2008; 134: 268-280. 
[93] Horie Y, Suzuki A, Kataoka E, Sasaki T, Hamada K, Sasaki J, et al. Hepatocyte-specific Pten deficiency results in steatohepatitis and hepatocellular carcinomas. J Clin Invest 2004; 113: 1774-1783.

[94] Stiles B, Wang Y, Stahl A, Bassilian S, Lee W P, Kim Y J, et al. Liver-specific deletion of negative regulator Pten results in fatty liver and insulin hypersensitivity Proc Natl Acad Sci U S A 2004; 101: 2082-2087.

[95] Liu J, Visser-Grieve S, Boudreau J, Yeung B, Lo S, Chamberlain G, et al. Insulin activates the insulin receptor to downregulate the PTEN tumour suppressor. Oncogene 2014; 33: 3878-3885.

[96] Standaert M L, Sajan M P, Miura A, Kanoh Y, Chen H C, Farese R V, Jr., et al. Insulin-induced activation of atypical protein kinase $C$, but not protein kinase $B$, is maintained in diabetic (ob/ob and Goto-Kakazaki) liver. Contrasting insulin signaling patterns in liver versus muscle define phenotypes of type 2 diabetic and high fatinduced insulin-resistant states. J Biol Chem 2004; 279: 24929-24934.

[97] Chettouh H, Fartoux L, Aoudjehane L, Wendum D, Claperon A, Chretien Y, et al. Mitogenic insulin receptor-A is overexpressed in human hepatocellular carcinoma due to EGFR-mediated dysregulation of RNA splicing factors. Cancer Res 2013; 73: 3974-3986.

[98] Belfiore A, Frasca F, Pandini G, Sciacca L, Vigneri R. Insulin receptor isoforms and insulin receptor/insulin-like growth factor receptor hybrids in physiology and disease. Endocr Rev 2009; 30: 586-623.

[99] Malaguarnera R, Sacco A, Voci C, Pandini G, Vigneri R, Belfiore A. Proinsulin binds with high affinity the insulin receptor isoform $A$ and predominantly activates the mitogenic pathway. Endocrinology 2012; 153: 2152-2163. 
[100] Breuhahn K, Schirmacher P. Reactivation of the insulin-like growth factor-II signaling pathway in human hepatocellular carcinoma. World J Gastroenterol 2008; 14: $1690-1698$.

[101] Tanaka S, Wands J R. Insulin receptor substrate 1 overexpression in human hepatocellular carcinoma cells prevents transforming growth factor beta1-induced apoptosis. Cancer Res 1996; 56: 3391-3394.

[102] Boissan M, Beurel E, Wendum D, Rey C, Lecluse Y, Housset C, et al. Overexpression of insulin receptor substrate-2 in human and murine hepatocellular carcinoma. Am J Pathol 2005; 167: 869-877.

[103] Cantarini M C, De La Monte S M, Pang M, Tong M, D'errico A, Trevisani F, et al. Aspartyl-asparagyl beta hydroxylase over-expression in human hepatoma is linked to activation of insulin-like growth factor and notch signaling mechanisms. Hepatology 2006; 44: 446-457.

[104] Longato L, De La Monte S, Kuzushita N, Horimoto M, Rogers A B, Slagle B L, et al. Overexpression of insulin receptor substrate-1 and hepatitis Bx genes causes premalignant alterations in the liver. Hepatology 2009; 49: 1935-1943.

[105] Yoshikawa H, Matsubara K, Qian G S, Jackson P, Groopman J D, Manning J $\mathrm{E}$, et al. SOCS-1, a negative regulator of the JAK/STAT pathway, is silenced by methylation in human hepatocellular carcinoma and shows growth-suppression activity. Nat Genet 2001; 28: 29-35.

[106] Calvisi D F, Ladu S, Gorden A, Farina M, Conner E A, Lee J S, et al. Ubiquitous activation of Ras and Jak/Stat pathways in human HCC. Gastroenterology 2006; 130: 1117-1128.

[107] Sze K M, Wong K L, Chu G K, Lee J M, Yau T O, Ng I O. Loss of phosphatase and tensin homolog enhances cell invasion and migration through AKT/Sp-1 
transcription factor/matrix metalloproteinase 2 activation in hepatocellular carcinoma and has clinicopathologic significance. Hepatology 2011; 53: 1558-1569.

[108] Yamashita $T$, Honda $M$, Takatori $H$, Nishino $R$, Minato $H$, Takamura $H$, et al. Activation of lipogenic pathway correlates with cell proliferation and poor prognosis in hepatocellular carcinoma. J Hepatol 2009; 50: 100-110.

[109] Calvisi D F, Wang C, Ho C, Ladu S, Lee S A, Mattu S, et al. Increased lipogenesis, induced by AKT-mTORC1-RPS6 signaling, promotes development of human hepatocellular carcinoma. Gastroenterology 2011; 140: 1071-1083.

[110] Li C, Yang W, Zhang J, Zheng X, Yao Y, Tu K, et al. SREBP-1 has a prognostic role and contributes to invasion and metastasis in human hepatocellular carcinoma. International journal of molecular sciences 2014; 15: 7124-7138.

[111] Evert M, Calvisi D F, Evert K, De Murtas V, Gasparetti G, Mattu S, et al. VAKT murine thymoma viral oncogene homolog/mammalian target of rapamycin activation induces a module of metabolic changes contributing to growth in insulininduced hepatocarcinogenesis. Hepatology 2012; 55: 1473-1484.

[112] Nemazanyy I, Espeillac C, Pende M, Panasyuk G. Role of PI3K, mTOR and Akt2 signalling in hepatic tumorigenesis via the control of PKM2 expression. Biochemical Society transactions 2013; 41: 917-922.

[113] Chen Z, Wang Z, Guo W, Zhang Z, Zhao F, Zhao Y, et al. TRIM35 Interacts with pyruvate kinase isoform M2 to suppress the Warburg effect and tumorigenicity in hepatocellular carcinoma. Oncogene 2014.

[114] Pollak M. The insulin and insulin-like growth factor receptor family in neoplasia: an update. Nat Rev Cancer 2012; 12: 159-169. 
[115] Rose D P, Vona-Davis L. The cellular and molecular mechanisms by which insulin influences breast cancer risk and progression. Endocr Relat Cancer 2012; 19: R225-241.

[116] Bonefeld K, Moller S. Insulin-like growth factor-I and the liver. Liver Int 2011; 31: 911-919.

[117] Hung T M, Ho C M, Liu Y C, Lee J L, Liao Y R, Wu Y M, et al. Up-regulation of microRNA-190b plays a role for decreased IGF-1 that induces insulin resistance in human hepatocellular carcinoma. PLoS One 2014; 9: e89446.

[118] Cirillo D, Rachiglio A M, La Montagna R, Giordano A, Normanno N. Leptin signaling in breast cancer: an overview. Journal of cellular biochemistry 2008; 105 : 956-964.

[119] Bartella V, Cascio S, Fiorio E, Auriemma A, Russo A, Surmacz E. Insulindependent leptin expression in breast cancer cells. Cancer Res 2008; 68: 49194927.

[120] Wang S N, Lee K T, Ker C G. Leptin in hepatocellular carcinoma. World J Gastroenterol 2010; 16: 5801-5809.

[121] Duan X F, Tang P, Li Q, Yu Z T. Obesity, adipokines and hepatocellular carcinoma. Int J Cancer 2013; 133: 1776-1783.

[122] Ding X, Saxena N K, Lin S, Xu A, Srinivasan S, Anania F A. The roles of leptin and adiponectin: a novel paradigm in adipocytokine regulation of liver fibrosis and stellate cell biology. Am J Pathol 2005; 166: 1655-1669.

[123] Aleffi S, Petrai I, Bertolani C, Parola M, Colombatto S, Novo E, et al. Upregulation of proinflammatory and proangiogenic cytokines by leptin in human hepatic stellate cells. Hepatology 2005; 42: 1339-1348. 
[124] Choi S S, Syn W K, Karaca G F, Omenetti A, Moylan C A, Witek R P, et al. Leptin promotes the myofibroblastic phenotype in hepatic stellate cells by activating the hedgehog pathway. J Biol Chem 2010; 285: 36551-36560.

[125] Saxena N K, Sharma D, Ding X, Lin S, Marra F, Merlin D, et al. Concomitant activation of the JAK/STAT, PI3K/AKT, and ERK signaling is involved in leptinmediated promotion of invasion and migration of hepatocellular carcinoma cells. Cancer Res 2007; 67: 2497-2507.

[126] Sharma D, Wang J, Fu P P, Sharma S, Nagalingam A, Mells J, et al. Adiponectin antagonizes the oncogenic actions of leptin in hepatocellular carcinogenesis. Hepatology 2010; 52: 1713-1722.

[127] Lee Y, Wang M Y, Kakuma T, Wang Z W, Babcock E, Mccorkle K, et al. Liporegulation in diet-induced obesity. The antisteatotic role of hyperleptinemia. J Biol Chem 2001; 276: 5629-5635.

[128] Safar Zadeh E, Lungu A O, Cochran E K, Brown R J, Ghany M G, Heller T, et al. The liver diseases of lipodystrophy: the long-term effect of leptin treatment. $J$ Hepatol 2013; 59: 131-137.

[129] Hickman I J, Powell E E, Prins J B, Clouston A D, Ash S, Purdie D M, et al. In overweight patients with chronic hepatitis $\mathrm{C}$, circulating insulin is associated with hepatic fibrosis: implications for therapy. J Hepatol 2003; 39: 1042-1048.

[130] Bugianesi E, Marchesini G, Gentilcore E, Cua I H, Vanni E, Rizzetto M, et al. Fibrosis in genotype 3 chronic hepatitis $C$ and nonalcoholic fatty liver disease: Role of insulin resistance and hepatic steatosis. Hepatology 2006; 44: 1648-1655.

[131] Moucari R, Asselah T, Cazals-Hatem D, Voitot H, Boyer N, Ripault M P, et al. Insulin resistance in chronic hepatitis C: association with genotypes 1 and 4 , serum HCV RNA level, and liver fibrosis. Gastroenterology 2008; 134: 416-423. 
[132] Naveau S, Lamouri K, Pourcher G, Njike-Nakseu M, Ferretti S, Courie R, et al. The diagnostic accuracy of transient elastography for the diagnosis of liver fibrosis in bariatric surgery candidates with suspected NAFLD. Obesity surgery 2014; $24: 1693-$ 1701.

[133] Bambha K, Wilson L A, Unalp A, Loomba R, Neuschwander-Tetri B A, Brunt E $M$, et al. Coffee consumption in NAFLD patients with lower insulin resistance is associated with lower risk of severe fibrosis. Liver Int 2014; 34: 1250-1258.

[134] Svegliati-Baroni G, Ridolfi F, Di Sario A, Casini A, Marucci L, Gaggiotti G, et al. Insulin and insulin-like growth factor-1 stimulate proliferation and type I collagen accumulation by human hepatic stellate cells: differential effects on signal transduction pathways. Hepatology 1999; 29: 1743-1751.

[135] Paradis V, Perlemuter G, Bonvoust F, Dargere D, Parfait B, Vidaud M, et al. High glucose and hyperinsulinemia stimulate connective tissue growth factor expression: a potential mechanism involved in progression to fibrosis in nonalcoholic steatohepatitis. Hepatology 2001; 34: 738-744.

[136] Bishayee A, Darvesh A S. Angiogenesis in hepatocellular carcinoma: a potential target for chemoprevention and therapy. Current cancer drug targets 2012; 12: 1095-1118.

[137] Vona-Davis L, Rose D P. Angiogenesis, adipokines and breast cancer. Cytokine \& growth factor reviews 2009; 20: 193-201.

[138] Liu Y, Petreaca M, Martins-Green M. Cell and molecular mechanisms of insulin-induced angiogenesis. Journal of cellular and molecular medicine 2009; 13 : 4492-4504. 
[139] Heidegger I, Kern J, Ofer P, Klocker H, Massoner P. Oncogenic functions of IGF1R and INSR in prostate cancer include enhanced tumor growth, cell migration and angiogenesis. Oncotarget 2014; 5: 2723-2735.

[140] Treins C, Giorgetti-Peraldi S, Murdaca J, Semenza G L, Van Obberghen E. Insulin stimulates hypoxia-inducible factor 1 through a phosphatidylinositol 3kinase/target of rapamycin-dependent signaling pathway. J Biol Chem 2002; 277 : 27975-27981.

[141] Yamagishi S, Kawakami T, Fujimori H, Yonekura H, Tanaka N, Yamamoto Y, et al. Insulin stimulates the growth and tube formation of human microvascular endothelial cells through autocrine vascular endothelial growth factor. Microvascular research 1999; 57: 329-339.

[142] Qiao J G, Wu L, Lei D X, Wang L. Insulin promotes sinusoidal endothelial cell proliferation mediated by upregulation of vascular endothelial growth factor in regenerating rat liver after partial hepatectomy. World J Gastroenterol 2005; 11 : 5978-5983.

[143] Zhang H, Fagan D H, Zeng X, Freeman K T, Sachdev D, Yee D. Inhibition of cancer cell proliferation and metastasis by insulin receptor downregulation. Oncogene 2010; 29: 2517-2527.

[144] Shaw L M. The insulin receptor substrate (IRS) proteins: at the intersection of metabolism and cancer. Cell Cycle 2011; 10: 1750-1756.

[145] Dombrowski F, Bannasch P, Pfeifer U. Hepatocellular neoplasms induced by low-number pancreatic islet transplants in streptozotocin diabetic rats. Am J Pathol 1997; 150: 1071-1087. 
[146] Dombrowski F, Mathieu C, Evert M. Hepatocellular neoplasms induced by lownumber pancreatic islet transplants in autoimmune diabetic BB/Pfd rats. Cancer Res 2006; 66: 1833-1843.

[147] Evert M, Sun J, Pichler S, Slavova N, Schneider-Stock R, Dombrowski F. Insulin receptor, insulin receptor substrate-1, Raf-1, and Mek-1 during hormonal hepatocarcinogenesis by intrahepatic pancreatic islet transplantation in diabetic rats. Cancer research 2004; 64: 8093-8100.

[148] Nakamura A, Tajima K, Zolzaya K, Sato K, Inoue R, Yoneda M, et al. Protection from non-alcoholic steatohepatitis and liver tumourigenesis in high fat-fed insulin receptor substrate-1-knockout mice despite insulin resistance. Diabetologia 2012; 55: 3382-3391.

[149] Tanaka S, Mohr L, Schmidt E V, Sugimachi K, Wands J R. Biological effects of human insulin receptor substrate-1 overexpression in hepatocytes. Hepatology 1997; 26: 598-604.

[150] Hines I N, Hartwell H J, Feng Y, Theve E J, Hall G A, Hashway S, et al. Insulin resistance and metabolic hepatocarcinogenesis with parent-of-origin effects in AxB mice. Am J Pathol 2011; 179: 2855-2865.

[151] Tamada M, Suematsu M, Saya H. Pyruvate kinase M2: multiple faces for conferring benefits on cancer cells. Clin Cancer Res 2012; 18: 5554-5561.

[152] Dransfield D T, Cohen E H, Chang Q, Sparrow L G, Bentley J D, Dolezal O, et al. A human monoclonal antibody against insulin-like growth factor-Il blocks the growth of human hepatocellular carcinoma cell lines in vitro and in vivo. Mol Cancer Ther 2010; 9: 1809-1819.

[153] Desbois-Mouthon C, Baron A, Blivet-Van Eggelpoël M, Fartoux L, Venot C, Bladt $F$, et al. IGF-1R inhibition induces a resistance mechanism via the 
EGFR/HER3/AKT signaling pathway: rational basis for co-targeting IGF-1R and EGFR in hepatocellular carcinoma Clin Cancer Res 2009; 15: 5445-5456.

[154] Abou-Alfa G K, Capanu M, O'reilly E M, Ma J, Chou J F, Gansukh B, et al. A phase II study of cixutumumab (IMC-A12, NSC742460) in advanced hepatocellular carcinoma. J Hepatol 2014; 60: 319-324.

[155] Zhao H, Desai V, Wang J, Epstein D M, Miglarese M, Buck E. Epithelialmesenchymal transition predicts sensitivity to the dual IGF-1R/IR inhibitor OSI-906 in hepatocellular carcinoma cell lines. Mol Cancer Ther 2012; 11: 503-513.

[156] Yee D. A tale of two receptors: insulin and insulin-like growth factor signaling in cancer. Clin Cancer Res 2015; 21: 667-669. 


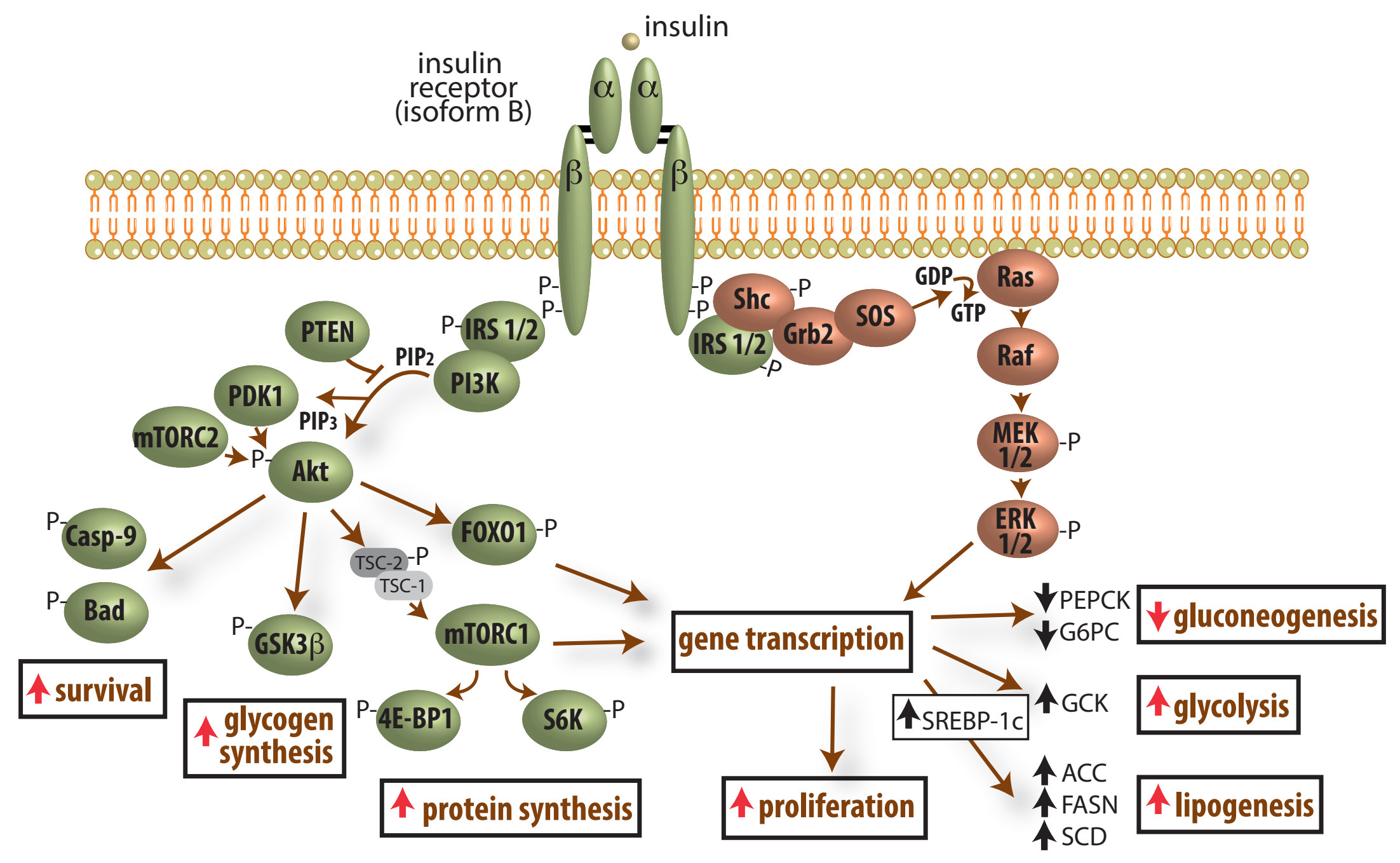


metabolic diabetes obesity syndrome $\downarrow$ insulin resistance

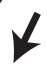

$\downarrow$

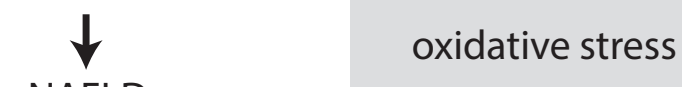

Jinsulin degradation

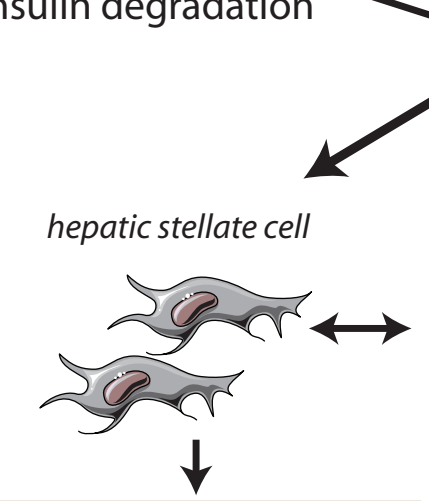

fibrogenesis inflammatory cytokines angiogenic cytokines

virus

$y$ alcohol $\checkmark$ chronic liver disease

chronic inflammation oxidative stress lipotoxicity hyperinsulinemia

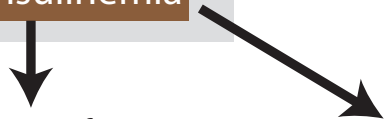

hepatocyte transformation

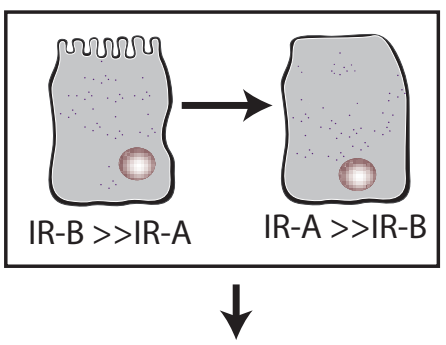

metabolism proliferation survival invasion endothelial cell

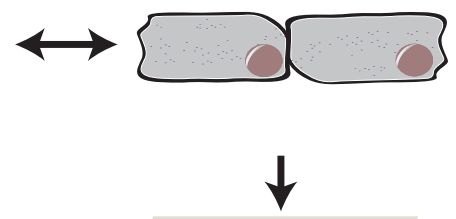

angiogenesis insulin resistance łinsulin degradation 